\title{
МЕТОДОЛОГИЯ ОПРЕДЕЛЕНИЯ МЕХАНИЧЕСКИХ ХАРАКТЕРИСТИК АТРАВМАТИЧЕСКИХ ДУГООБРАЗНЫХ МЕДИЦИНСКИХ ИГЛ
}

\author{
С.В. Словиков ${ }^{1}$, В.А. Самарцев ${ }^{2}$, В.А. Гаврилов ${ }^{2}$ \\ 1 Центр экспериментальной механики Пермского национального исследовательского политехнического \\ университета, Россия, 614990, Пермь, Комсомольский проспект, 29, e-mail: sslovikov@yandex.ru \\ 2 Кафедра общей хирургии № 1 Пермского государственного медицинского университета имени академика \\ Е.А. Вагнера, Россия, 614000, Пермь, ул. Петропавловская, 26, e-mail: gensurperm@mail.ru
}

\begin{abstract}
Аннотация. В настоящее время в хирургии наиболее широкое применение находят синтетические шовные материалы с заданными сроками рассасывания. Для уменьшения диаметра прокольного канала, а также снижения вероятности развития инфекции в области хирургического вмешательства современные нити различных диаметров комплектуются атравматическими дугообразными иглами такого же диаметра. Изготовленние данного вида игл потребовало изменения технологии, однако требования государственных стандартов остались прежними. На практике хирург часто сталкивается с проблемами, вызванными эксплуатационными механическими недостатками игл, выходящими за рамки существующих стандартов. С целью совершенствования методик экспериментального определения таких параметров была начата разработка методологии исследований дополнительных механических характеристик игл. Помимо уменьшения диаметра прокольного канала атравматические иглы не имеют ушка, что препятствует разволокнению шовного материала и увеличивает прочность межтканевых соединений. На основании проведенного анализа недостатков производства предложены параметры, характеризующие прочностные и деформационные свойства атравматических дугообразных медицинских игл, их износоустойчивость и качество изготовления соединения иглы с нитью. Были разработаны методики определения предлагаемых дополнительно к стандартным механических характеристик игл. Проведена отработка исследований по предлагаемым методикам и получены результаты для двух типов атравматических дугообразных медицинских игл. Представленные методики позволяют проводить механические испытания по изучению таких важных в практическом использовании параметров игл, как способность упруго деформироваться, стойкость к износу, снижение проникающих свойств и качество изготовления соединения иглы с нитью.
\end{abstract}

Ключевые слова: механические свойства, атравматическая дугообразная медицинская игла, экспериментальная механика, износоустойчивость игл, прочность игл.

\section{ВВЕДЕНИЕ}

В современной хирургии расширяется спектр шовных материалов [3, 8-11]. В настоящее время наиболее широкое применение находят синтетические шовные материалы с заданными сроками рассасывания $[12,13,15,16]$. Для уменьшения диаметра прокольного канала, а также снижения вероятности развития инфекции в

(C) Словиков С.В., Самарцев В.А., Гаврилов В.А., 2016

Словиков Станислав Васильевич, к.т.н., старший научный сотрудник Центра экспериментальной механики, Пермь

Самарцев Владимир Аркадьевич, д.м.н., профессор, завкафедрой общей хирургии № 1, Пермь Гаврилов Василий Александрович, к.м.н., доцент кафедры общей хирургии № 1, Пермь 
области хирургического вмешательства одним из наиболее применяемых в хирургии типом современного шовного материала является единая конструкция, состоящая из нити и атравматической дугообразной иглы $[1,4,14]$, имеющих одинаковый диаметр. Вид игл изменил технологию их изготовления, однако требования государственного стандарта остались прежними [2, 5, 6]. На практике хирург часто стакивается с проблемами, вызванными эксплуатационными механическими недостатками игл, выходящими за рамки существующих стандартов.

В Пермском национальном исследовательском политехническом университете на базе Центра экспериментальной механики (ЦЭМ ПНИПУ) были разработаны методики определения механических характеристик для одного из типов медицинского шовного материала - атравматических дугообразных медицинских игл. Помимо уменьшения диаметра прокольного канала, такие иглы не имеют ушка, что препятствует разволокнению шовного материала и увеличивает прочность межтканевых соединений. В то же время необходимо отметить возможные недостатки атравматических игл, вызванные низким качеством изготовления:

- деформирование иглы при выполнении шва;

- увеличение усилия при проколе при большом количестве стежков;

- разрыв соединения игла-нить при стягивании тканей.

Существующие стандартизованные методики позволяют определить только соответствие основных технических характеристик игл предъявляемым к ним требованиям. Но эти требования не всегда соответствуют реальным условиям применения.

Для выявления недостатков изготовления необходимо было предложить новые параметры механических свойств игл и методы их определения.

Таким образом, целью данной работы явились более глубокое исследование механических характеристик атравматических хирургических игл и разработка дополнительных требований к ним.

\section{МАТЕРИАЛЫ И МЕТОДЫ}

Условием проведения исследований по предлагаемой методике является соответствие игл ГОСТ 26641-85 [6]. Для решения задачи выявления недостатков производства игл необходимо определить такие механические свойства, как прочностные и деформационные параметры иглы, износоустойчивость и механический параметр, характеризующий качество изготовления соединения иглы с нитью.

\section{Методика исследования прочностных и деформационных свойств игл}

Для определения прочностных и деформационных свойств предлагается исследовать такие параметры, как прочность иглы, предел упругости и коэффициент жесткости.

Под прочностью иглы $\sigma_{\mathrm{B}}^{\mathrm{U}}$ в данной методике исследования подразумевается максимальная нагрузка, Н/ мм² $^{2}$ которую выдерживает игла, отнесенная к площади сечения $(\mathrm{S})$ в районе крепления иглодержателя при ее нагружении, как показано на рис. 1, $a$ и имитирующая прокалывание иглой ткани.

Жесткость иглы - способность упруго деформироваться без последующего изменения геометрических параметров. Характеризует жесткость иглы коэффициент жесткости $k, \mathrm{H} / \mathrm{Mм}$, который определяется как угол наклона кривой «сила - перемещение иглодержателя» на начальном линейном участке кривой. 
Предел упругости иглы $\sigma_{\text {y }}$ - это максимальная нагрузка $F_{\mathrm{y}}$, отнесенная к площади сечения $S$ в районе крепления иглодержателя, до которой игла не получает остаточных деформаций:

$$
\sigma_{\mathrm{y}}=\frac{F_{\mathrm{y}}}{S} .
$$

Нагрузку, соответствующую пределу упругости иглы, H, определяют из условия, когда

$$
\left(\frac{\frac{F_{\mathrm{y}}}{k}-\Delta l}{\Delta l}\right) 100=a,
$$

где $\Delta l$ - перемещение иглодержателя, мм; $k$ - коэффициент жесткости иглы, Н/мм; $a$ - относительная погрешность измерения перемещения, \%.

Для достаточно точного определения коэффициента жесткости класс точности прибора измерения перемещения должен быть не ниже 0,5. Таким образом, $a=0,5 \%$ или выше.

Изучение прочностных механических характеристик атравматических игл с использованием иглодержателя производится в следующем порядке.

Игла закрепляется в иглодержателе на расстоянии 2/3 длины от острия, затем производится нагружение по схеме, представленной на рис. $1, a$. В точке соприкосновения острия иглы и металлической опоры 3 выполняется кернение для создания в материале углубления таким образом, чтобы острие иглы не перемещалось при нагружении, тем самым исключается изменение плеча момента, действующего на иглу.

Датчик нагрузки измеряет силу, с которой игла давит на опору. Он должен иметь диапазон измерения от 0,1 до $1000 \mathrm{H}$ и обладать точностью измерения не хуже $\pm 0,1 \mathrm{H}$.

По результатам полученных данных строится прямая жесткости иглы, и по ней определяется предел упругости.

Испытания проводят не менее чем для пяти образцов иглы одного типа.

Результаты испытаний, а также данные статистической обработки заносят в таблицу, в которой указывают тип иглы, номер образца, прочность иглы $\sigma_{\mathrm{B}}^{\mathrm{U}}, \mathrm{H} / \mathrm{Mм}^{2}$, коэффициент жесткости иглы $k, \mathrm{H} / \mathrm{MM}^{2}$, предел упругости иглы $\sigma_{y}, \mathrm{H} / \mathrm{MM}^{2}$, математические ожидания параметров иглы $\left\langle\sigma_{\mathrm{B}}^{\mathrm{U}}\right\rangle,\langle k\rangle$ и $\left\langle\sigma_{y}\right\rangle$.
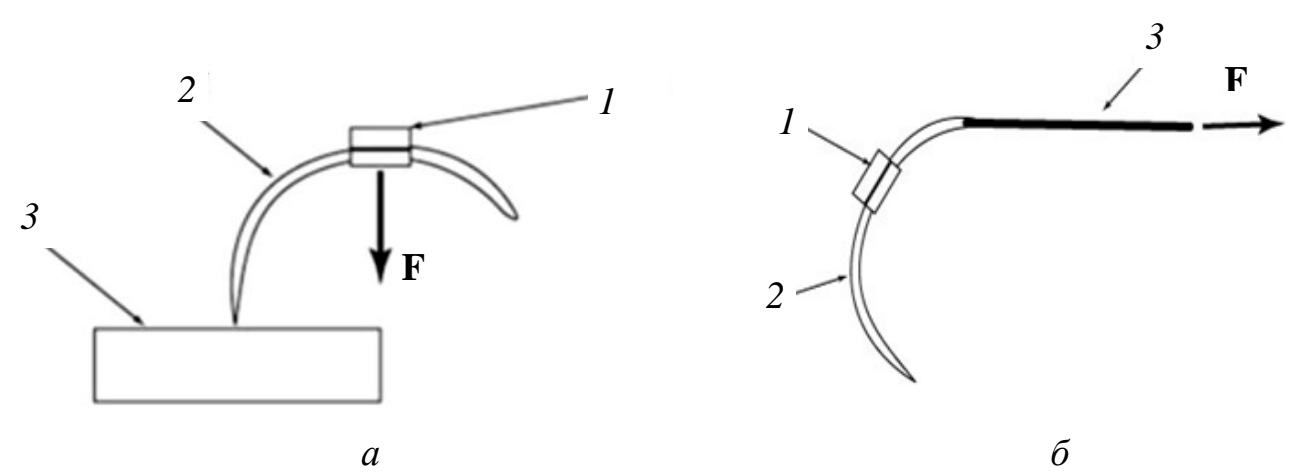

Рис. 1. Схема нагружения для определения прочности иглы (a) и нагружения иглы с нитью (б): 1 - иглодержатель, 2 - игла, 3 - опора, $\mathbf{F}$ - вектор нагружающей силы 


\section{Методика исследования износоустойчивости иглы}

Для определения стойкости иглы к износу введем специальные параметры.

Износостойкость иглы $N_{25 \%}-$ количество проколов ткани иглой без значительного (не более 25 \%) роста нагрузки при прокалывании.

Коэффициент износостойкости $I_{20}$ - отношение средней нагрузки с 18-го по 23-й прокол модельной ткани $F_{20}$ к $F_{0}$ :

$$
I_{20}=\frac{F_{0}}{F_{20}}
$$

где $F_{20}=\frac{\sum_{18}^{23} F_{i}}{6}$.

Модельной тканью является замша толщиной 0,7 мм (ГОСТ 3717-84. Замша. Технические условия [7]).

В связи с неоднородностью структуры прокалываемой ткани за усилие прокола новой иглой $F_{0}$ принимают среднюю нагрузку, возникающую при выполнении шести первых проколов на разных участках модели.

$$
F_{0}=\frac{\sum_{1}^{6} F_{i}}{6} .
$$

Количество проколов выбрано в результате проведенных в ЦЭМ ПНИПУ дополнительных статистических исследований. За шесть проколов любая игла не меняет свои механические свойства (так как должна соответствовать пунктам 2.7 и 3.7 ГОСТ 26641-85), а изменения в нагрузке связаны только с различием в плотности разных участков модельной ткани, т.е. попадания острия иглы в более плотные или менее плотные участки ткани. Также необходимо отметить, что если усреднение проводить по большему числу проколов, то начинает проявляться свойство затупления иглы [6].

Изучение характеристики износостойкости атравматических игл с использованием иглодержателя производится в следующем порядке.

Игла закрепляется в иглодержателе на расстоянии 2/3 длины от острия, затем производится нагружение аналогично схеме, представленной на рис. $1, a$, но вместо опоры 3 размещается пяльце с замшей.

Замеряют максимальную нагрузку при каждом проколе $F_{i}$. Меняют положение ткани после каждого прокола. После шести проколов рассчитывают среднее значение нагрузки для новой иглы по формуле (4). Принимают это значение за усилие прокола новой иглы.

Прокалывают ткань, меняя место прокола и замеряя максимальную нагрузку $F_{i}$ при каждом проколе. При достижении нагрузки $F_{i}$ на $25 \%$ больше, чем $F_{0}$, считают общее количество проколов $N_{25 \%}$.

Далее определяется коэффициент износостойкости $I_{20}$.

Полученные данные по испытаниям и результаты статистической обработки заносят в таблицу, где указывают номер образца, тип иглы, значение износостойкости иглы $N_{25 \%}$, математическое ожидание износостойкости иглы $<N_{25 \%}>$, коэффициент износостойкости $I_{20}$ и математическое ожидание коэффициента износостойкости $<I_{20}>$. 


\section{Методика исследования качества изготовления соединения иглы с нитью}

Для определения прочности соединения игла-нить введем следующей параметр: прочность соединения игла-нить $F_{m}$ - максимальная сила, Н, возникающая перед отрывом нити от иглы.

При определении прочности соединения игла-нить атравматическая игла закрепляется в иглодержателе на расстоянии 2/3 длины от острия, а затем производится нагружение по схеме, представленной на рис. 1,6 .

Скорость нагружения составляет 1 H/c. В процессе испытания фиксируется максимальная нагрузка $F_{m}^{\prime}$.

Данные результатов испытания и статистической обработки, такие как номер образца, тип иглы, значение прочности соединения игла-нить $F_{m}{ }^{\prime}, \mathrm{H}$, математическое ожидание $<F_{m}>$, заносят в таблицу.

В результате всей совокупности проведенных исследований данные измерений и вычислений сводятся в таблицу по типам игл и их производителям, где указывают: номер типа игл, наименование производителя игл, прочность, износостойкость, коэффициент износостойкости, диапазон коэффициента износостойкости после прошивания тканей различной плотности $I_{n \text { макс }}^{\prime} . I_{n \text { мин }}^{\prime}$ и прочность соединения игланить.

По результатам испытаний разрабатываются дополнительные требования к механическим характеристикам атравматических хирургических игл, а именно соответствие таким характеристикам, как прочность, износостойкость, прочность соединения игла-нить.

\section{Результаты}

Для отработки методик определения механических характеристик атравматических дугообразных медицинских игл была проведена серия испытаний. Пример исследуемой иглы показан на рис. 2. Представленная игла марки Surgilactin с индексом $D W 11515$, длиной 40 мм, степенью изгиба «1/2» имеет круглую форму поперечного сечения. Площадь сечения в месте крепления иглодержателя составляет 3,12 $\mathrm{Mм}^{2}$.

В результате проведенных экспериментов по представленной выше методике были получены диаграммы нагружения, показанные на рис. 3.

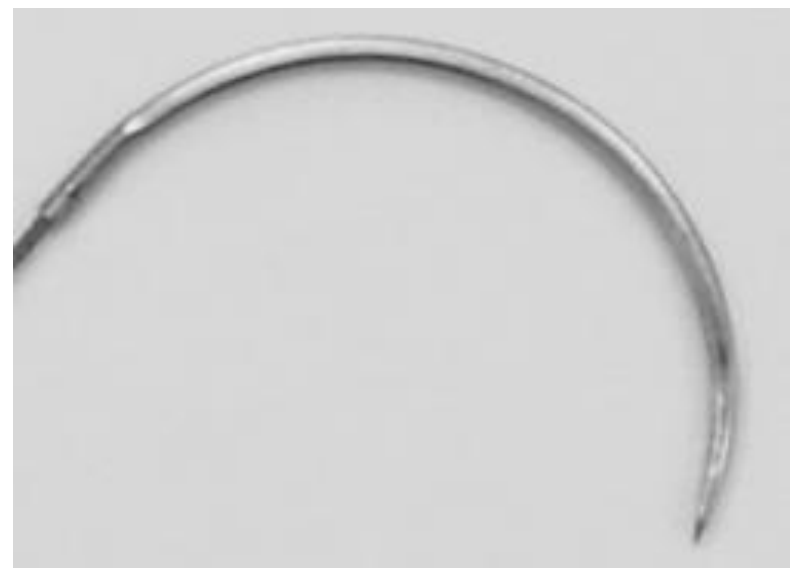

Рис. 2. Исследуемая дугообразная медицинская игла 


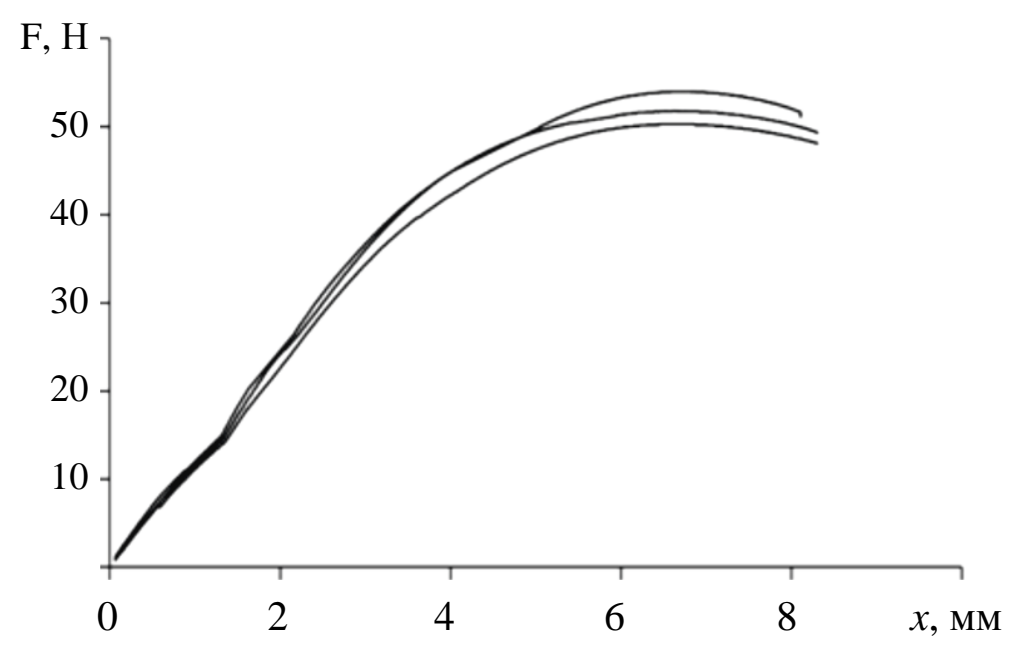

Рис. 3. Диаграммы «сила $F$ - перемещение иглодержателя $x$ »

После статистической обработки по методу коэффициентов Стьюдента с доверительной вероятностью 95 \% были получены следующие результаты: прочность иглы $<\sigma_{\text {в }}^{\text {n }}>\quad-16,49 \pm 1,00 \mathrm{H} / \mathrm{Mм}^{2}$; коэффициент жесткости иглы $<k>-$ $12,67 \pm 0,64 \mathrm{H} / \mathrm{Mм}$; упругость иглы $<\sigma_{y}>-3,32 \pm 0,11 \mathrm{H} / \mathrm{Mм}^{2}$.

При исследовании износоустойчивости были выполнены серии испытаний по 50 проколов иглой типа МО-45.

В результате по расчетам в соответствии с формулами (2) и (3) получены значения: $F_{0}=3,53 \mathrm{H}, F_{20}=4,27 \mathrm{H}, I_{20}=0,8, N_{25 \%}=48$.

Для шовного материала типа «СТ-1, игла 40 мм $1 / 2$ с» получено значение математического ожидания прочности соединения игла-нить $<F_{m}>=33 \mathrm{H}$.

\section{ЗАКЛЮЧЕНИЕ}

На данном этапе разработки методологии исследований механических характеристик дугообразной медицинской иглы можно сделать заключение о том, что представленные методики позволяют проводить механические испытания по изучению таких важных в практическом использовании параметров игл, как способность упруго деформироваться, стойкость к износу, снижение проникающих свойств, качество изготовления соединения иглы с нитью.

В дальнейшем необходимо проведение комплекса исследований различных типов атравматических игл разных производителей. Это позволит разработать дополнительные технические требования к атравматическим дугообразным иглам, усовершенствовать существующие отраслевые и государственные стандарты их изготовления.

\section{БЛАГОДАРНОСТИ}

Работа выполнена при финансовой поддержке Российского фонда фундаментальных исследований (грант №15-08-08247-а «Исследование механических свойств функциональных хирургических материалов в условиях воздействия биологических сред»). 


\section{СПИСОК ЛИТЕРАТУРЫ}

1. Байчоров Э.Х., Дубовой Л.М., Пасечников А.Д. Современный шовный материал, применяемый в хирургии // Здоровье - системное качество человека: сб. ст. - Ставрополь, 1999. - С. 328-334.

2. Бонцевич Д.Н. Прочность и травматичность хирургических нитей на основе полиамида, используемых в республике Беларусь // Проблемы здоровья и экологии. - 2015. - № 1 (43). - С. 67-72.

3. Бонцевич Д.Н. Хирургический шовный материал. - М.: Интеграция, 2005. - 118 с.

4. Буянов В.М., Егиев В.Н., Удотов О.А. Хирургический шов. - М.: График Групп, 2000. - 93 с.

5. ГОСТ 25981-83. Иглы хирургические. Общие технические условия [Электронный pecypc]. - URL: vsegost.com/Catalog/21/21059.shtml (дата обращения: 10.06.2016).

6. ГОСТ 26641-85. Иглы атравматические. Общие технические требования и методы испытаний [Электронный ресурс]. - URL: http://vsegost.com/Catalog/20/20226.shtml (дата обращения: 10.06.2016).

7. ГОСТ 3717-84. Замша. Технические условия [Электронный ресурc]. - URL: http:// http://vsegost.com/Catalog/20/20689.shtml (дата обращения: 10.06.2016).

8. Егиев В.Н. Шовный материал // Хирургия. Журнал им. Н.И. Пирогова. - 1998. - № 3. - С. $33-38$.

9. Кабешев Б.О., Бонцевич Д.Н., Васильков А.Ю. Антибактериальный шовный материал // Хирургия. Восточная Европа. - 2012. - № 3. - С. 294-296.

10. Мохов Е.М., Чумаков Р.Ю., Сергеев А.Н. Применение биологически активных шовных материалов в неотложной хирургии органов брюшной полости // Вестник хирургии им. И.И. Грекова. - 2012. № 3. - С. 24-28.

11. Петрова М.Б., Мохов Е.М., Сергеев А.Н., Серов Е.В. Экспериментально-гистологический анализ влияния биологически активных шовных материалов на течение раневого процесса в коже // Современные проблемы науки и образования. - 2015. - № 6. - С. 302.

12. Самарцев В.А., Вильдеман В.Э., Словиков С.В., Гаврилов В.А., Федоров А.Е. Стратегия применения современных шовных материалов с антимикробными свойствами в абдоминальной хирургии // Пермский медицинский журнал. - 2010. - Т. 27, № 5. - С. 104-108.

13. Словиков С.В., Янкин А.С. Исследование механических свойств хирургических синтетических шовных материалов в условиях биодеградации // Математическое моделирование в естественных науках. - 2015. - Т. 1. - С. 416-418.

14. Соединение тканей в хирургии / под ред. Б.О. Милькова. - Черновцы: Редакционно-издательский отдел облполиграфиздата, 1991. - 112 с.

15. Федоров А.Е., Самарцев В.А., Гаврилов В.А., Вильдеман В.Э., Словиков С.В. Экспериментальное исследование механических свойств современных хирургических рассасывающихся шовных материалов // Российский журнал биомеханики. - 2009. - Т. 13, № 4. - С. 78-84.

16. Hench L.L., Jones J.R. Biomaterials, artificial organs and tissue engineering. - Boca Raton, FL: Woodhead Publishing Limited, 2005. - 284 p.

\section{METHODOLOGY FOR DETERMINING MECHANICAL PROPERTIES OF ATRAUMATIC ARCUATE MEDICAL NEEDLES}

\section{S.V. Slovikov, V.A. Samartsev, V.A. Gavrilov (Perm, Russia)}

In modern surgery, the range of the applied sutural materials is constantly expanding. Today, the synthetic absorbable sutural materials find the broadest application. For reduction of diameter of the puncture-channel and decrease in probability of development of surgical site infection, the atraumatic modern suture materials of various diameters are completed with atraumatic arc-shaped needles. This type of needles has changed technology of their production. However, the requirements to state standards have remained the same. In practice, the surgeon often deals with the problems caused by the operational mechanical shortcomings of needles, which are beyond the existing standards. The aim of this study was improvement of experimental determination techniques of additional needle mechanical characteristics. For reducing diameter of the puncture channel, atraumatic needle do not have lugs, which prevent the suture fibre production and increase strength of intertissue compounds. Based on the conducted analysis of manufacturing defects, we get the parameters characterizing strength 
and deformation properties of atraumatic arc-shaped surgical needles, their wear resistance and the quality of producing compound of a needle with a thread. Procedures for determining the mechanical characteristics of needles in addition to the standard were elaborated. Researches on the offered techniques were carried out and results for two types of atraumatic arc-shaped medical needles were received. Two types of atraumatic needles were researched with the original presented methods. These methods allow us to study important practical parameters of needles: elastic deformation, wear resistance, reduction-penetrating properties, quality of production of compound needle-thread.

Key words: mechanical properties, atraumatic arc-shaped surgical needle, experimental mechanics, wear resistance of needles, durability of needles.

Получено 16 июня 2016 